Research Article

\title{
Effects of Variable Humidity on the Creep Behavior of Concrete and the Long-Term Deflection of RC Beams
}

\author{
Pengfei Li $\mathbb{D}^{1}$ and Shiqin He $\mathbb{D}^{2}$ \\ ${ }^{1}$ Department of Harbor, Waterway and Coastal Engineering, Chongqing Jiaotong University, Chongqing 400074, China \\ ${ }^{2}$ College of Civil Engineering, North China University of Technology, Beijing 100144, China \\ Correspondence should be addressed to Shiqin He; heshiqin@ncut.edu.cn
}

Received 26 March 2018; Revised 30 September 2018; Accepted 14 October 2018; Published 29 October 2018

Academic Editor: Carlos Chastre

Copyright (c) 2018 Pengfei Li and Shiqin He. This is an open access article distributed under the Creative Commons Attribution License, which permits unrestricted use, distribution, and reproduction in any medium, provided the original work is properly cited.

\begin{abstract}
The influences of variable humidity on the creep behaviors of concrete and the long-term deflections of RC beams are analyzed in this paper. A total of 6 prismatic specimens and $5 \mathrm{RC}$ beams were subjected to sustained loads and 3 types of variable humidity conditions for 331 days. The creep strains of the prismatic specimens and the deflections of the RC beams were recorded to investigate the long-term deformation characteristics. The test results reveal that both the creep strain and the deflection of specimens under cyclic humidity conditions exhibit approximately linear tendencies that are obviously less than those of specimens exposed only to natural air. During certain wetting cycles, the deformation rate became slower and the creep strain even recovered with an increase in the humidity, especially for shorter wetting-drying cycles. Long-term deflections predicted using the CEB-FIP 90 and ACI 209R models were compared with the test results to evaluate the versatility of these current specifications. The findings included rather large errors between the predicted results and experimental data when the average relative humidity was adopted in the analytical models.
\end{abstract}

\section{Introduction}

A major property of concrete is its vulnerability to creep, which is a time-dependent deformation mechanism under a sustained load [1-5]. Long-term deflections of reinforced concrete (RC) beams due to creep may cause cracking and damage, significantly compromising the durability and sustainability of concrete structures [6-8]. Concrete creep and the associated long-term deflections are both influenced by environmental conditions (e.g., the temperature and ambient humidity) [9-13], mixing proportions [14, 15], material properties [16], and applied stresses [17]. Throughout their service life, concrete structures will be simultaneously exposed to loading in conjunction with various environmental conditions, particularly variable levels of humidity. However, the long-term behavior of concrete under such a variable humidity remains rather unknown and merits further investigation.
For the dominant theories, the pore pressure due to water surface tension under high or moderate relative humidity and the increase of surface energy of gel under low relative humidity are the primary mechanism of the shrinkage $[18,19]$. The viscous flow of capillary and gel water has been considered as the main mechanism of creep [1]. Based on these concepts, properties of liquid inside micropores will control the mechanical behaviors of concrete [20]. In recent years, numerous investigations have been conducted to study the effects of humidity on the behaviors of concrete creep. The interior water status of pore structures is believed to be associated with the ambient humidity, and thus, the deformation of concrete will be much higher when it is simultaneously subjected to drying and loading [21]. Supplementary deformation is composed of so-called drying creep, which is also known as Pickett's effect [22].

In the past decade, creep behavior of concrete under constant humidity has been widely investigated. Laboratory 
test results showed that the creep of a specimen exposed to cyclic humidity may be twice as large as the creep of a specimen exposed to a constant humidity equal to the average humidity [23-25]. However, very few studies have addressed the behavior of concrete under variable humidity conditions, and limited experimental data show that swelling occurs when the water content increases $[24,25]$. Because the relevant test data are discrete, no uniform conclusion has been reached regarding the deformation characteristics and influencing mechanisms of variable humidity-associated concrete creep. A simple formula, which is partly empirical, partly based on the diffusion theory, is proposed and is calibrated by comparisons with test data from the literature [25]. But such explanations generally do not include a discussion of the uniqueness and reversibility of the phenomenon. Therefore, the long-term behavior of concrete under variable humidity conditions coupled with loading remains merits of investigation.

Extensive research has been performed to predict the long-term creep and deformation of concrete. As a result, several simplified methods have been developed. These existing methods generally establish the environmental relative humidity $(\mathrm{RH})$ as a constant and set the range of applications accordingly. However, disparities in the origins and numbers of parameters explicitly accounted for in these models can lead to significant differences in the predicted deflections. Consequently, there is no overall reliable model available for the prediction of creep deformation under variable humidity conditions.

Therefore, in this study, laboratory tests were designed to provide the creep behavior of concrete and the longterm deflection of RC beams subjected to variable humidity. Three types of exposure conditions were established in the laboratory to investigate the effects of variable humidity. A series of prismatic specimens and RC beams were subjected to sustained loads and variable humidity conditions for 331 days. Both the creep strain in the prismatic specimens and the deflections of the RC beams were recorded to investigate the characteristics of their long-term deformation. Furthermore, the creep coefficients provided by the CEB-FIP 90 [26] and ACI 209R [27] models were compared with the experimental results to evaluate the versatility of these current specifications.

\section{Experimental Test Program}

2.1. Materials and Mixtures. The concrete mixture shown in Table 1 was adopted in the present study. The components consisted of ordinary Portland cement (PO 42.5), coarse aggregate with a maximum gravel diameter of $20 \mathrm{~mm}$, fine aggregate with a fineness modulus of 2.6, and polycarboxylate-based superplasticizer. The 7-day and 28day compressive strengths were $31.4 \mathrm{MPa}$ and $51.0 \mathrm{MPa}$, respectively. Two types of steel bars were used in the $\mathrm{RC}$ beams; the mechanical properties of the steel bars are shown in Table 2.
2.2. Test Setup of the Creep Behavior. To investigate the effects of variable humidity conditions on the creep behavior of concrete, nine prismatic specimens were cast with a length of $550 \mathrm{~mm}$, a width of $150 \mathrm{~mm}$, and a depth of $150 \mathrm{~mm}$, as shown in Figure 1. After 43 days of standard curing under standard conditions $\left(20 \pm 1^{\circ} \mathrm{C},>90 \% \mathrm{RH}\right)$, the prismatic specimens were subjected to sustained loading using the creep apparatus. As shown in Figure 2, two specimens were fixed into the creep apparatus by means of two steel plates, after which the specimens were tested simultaneously under direct compression. The loading level was set at $30 \%$ of the peak load (calculated as $276 \mathrm{kN}$ for all of the specimens).

To ensure the accuracy and long-term stability of the measurements, a hand-held strain device with a digital display was used to measure the creep deformation every day. Two measurement points spaced at $250 \mathrm{~mm}$ were firmly attached to the surface of each specimen. The measurement process is shown in Figure 2.

After loading, all of the prismatic specimens were divided into three series, as shown in Table 3. Three different types of exposure conditions were considered in this study. For exposure condition 1, the specimens were exposed to natural air as the control. For exposure condition 2, the specimens were first sprayed with water for 7 days and were then exposed to air to allow them to dry for another 7 days. Figure 2 shows the details of the spray system. To ensure uniform moisture conditions for each specimen, an immersed pump was used in conjunction with four PVC pipes to spray tap water onto the surface of each specimen. For exposure condition 3, the same spray system was used; instead, the single variable was the wetting-drying cycle, which lasted for 2 days (wetting for 1 day and drying for 1 day). Specimens CR-A-S, CR-B-S, and CR-C-S were tested without loading to measure the shrinkage under different exposure conditions. Meanwhile, creep strain can be calculated by

$$
\varepsilon_{\mathrm{cp}}\left(t, t_{0}\right)=\varepsilon_{\mathrm{e}}\left(t, t_{0}\right)-\varepsilon_{\mathrm{sh}}\left(t, t_{0}\right),
$$

where $t$ and $t_{0}$ are the loading age and the time after loading, respectively, $\varepsilon_{\mathrm{cp}}\left(t, t_{0}\right)$ and $\varepsilon_{\mathrm{sh}}\left(t, t_{0}\right)$ are the creep strain and shrinkage strain, respectively, and $\varepsilon_{\mathrm{e}}\left(t, t_{0}\right)$ is the total strain measured with the hand-held strain device.

2.3. Long-Term Deflection Test Setup. Figure 3 shows the dimensions and the reinforcement properties of the RC beams. Ten beams were cast with a width of $120 \mathrm{~mm}$, a depth of $150 \mathrm{~mm}$, and a length of $2100 \mathrm{~mm}$. Deformed HRB335 steel with a diameter of $12 \mathrm{~mm}$ was used as the tension reinforcement. Two steel bars were used in each beam and were hooked to avoid bond failure. Smooth HPB235 steel with a diameter of $10 \mathrm{~mm}$ was used for the stirrups and the top-layer steel bars. Stirrups were placed with a spacing of $100 \mathrm{~mm}$ in the shear span $(700 \mathrm{~mm})$. Meanwhile, stirrups and top-layer steel bars were not used in the moment span $(500 \mathrm{~mm})$ to avoid the effects of reinforcement on concrete creep in the compression zone. 
TABLe 1: Properties and mixture proportion of the concrete used in the present study.

\begin{tabular}{lcccccc}
\hline $\begin{array}{l}\text { Water } \\
\left(\mathrm{kg} / \mathrm{m}^{3}\right)\end{array}$ & $\begin{array}{c}\text { Cement } \\
\left(\mathrm{kg} / \mathrm{m}^{3}\right)\end{array}$ & $\begin{array}{c}\text { Coarse aggregate } \\
\left(\mathrm{kg} / \mathrm{m}^{3}\right)\end{array}$ & $\begin{array}{c}\text { Fine aggregate } \\
\left(\mathrm{kg} / \mathrm{m}^{3}\right)\end{array}$ & $\begin{array}{c}\text { Plasticizer } \\
\left(\mathrm{kg} / \mathrm{m}^{3}\right)\end{array}$ & $\begin{array}{c}\text { Slump } \\
(\mathrm{mm})\end{array}$ & $\begin{array}{c}\text { Elastic modulus } \\
(\mathrm{GPa})\end{array}$ \\
\hline 195 & 390 & 1162 & 653 & 1.6 & 180 & 36.7 \\
\hline
\end{tabular}

TABLE 2: Mechanical properties of the steel bars used in the present study.

\begin{tabular}{lcccc}
\hline Bar type & Diameter $(\mathrm{mm})$ & Yield stress $(\mathrm{MPa})$ & Ultimate strength $(\mathrm{MPa})$ & Elastic modulus $(\mathrm{GPa})$ \\
\hline HRB335 & 12 & 350 & 512 & 215 \\
HPB235 & 10 & 235 & 360 & 195 \\
\hline
\end{tabular}
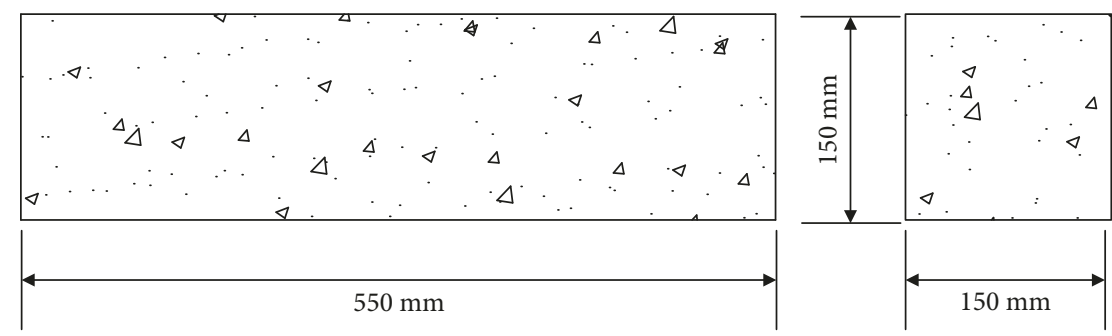

Figure 1: Dimensions of a prism specimen.

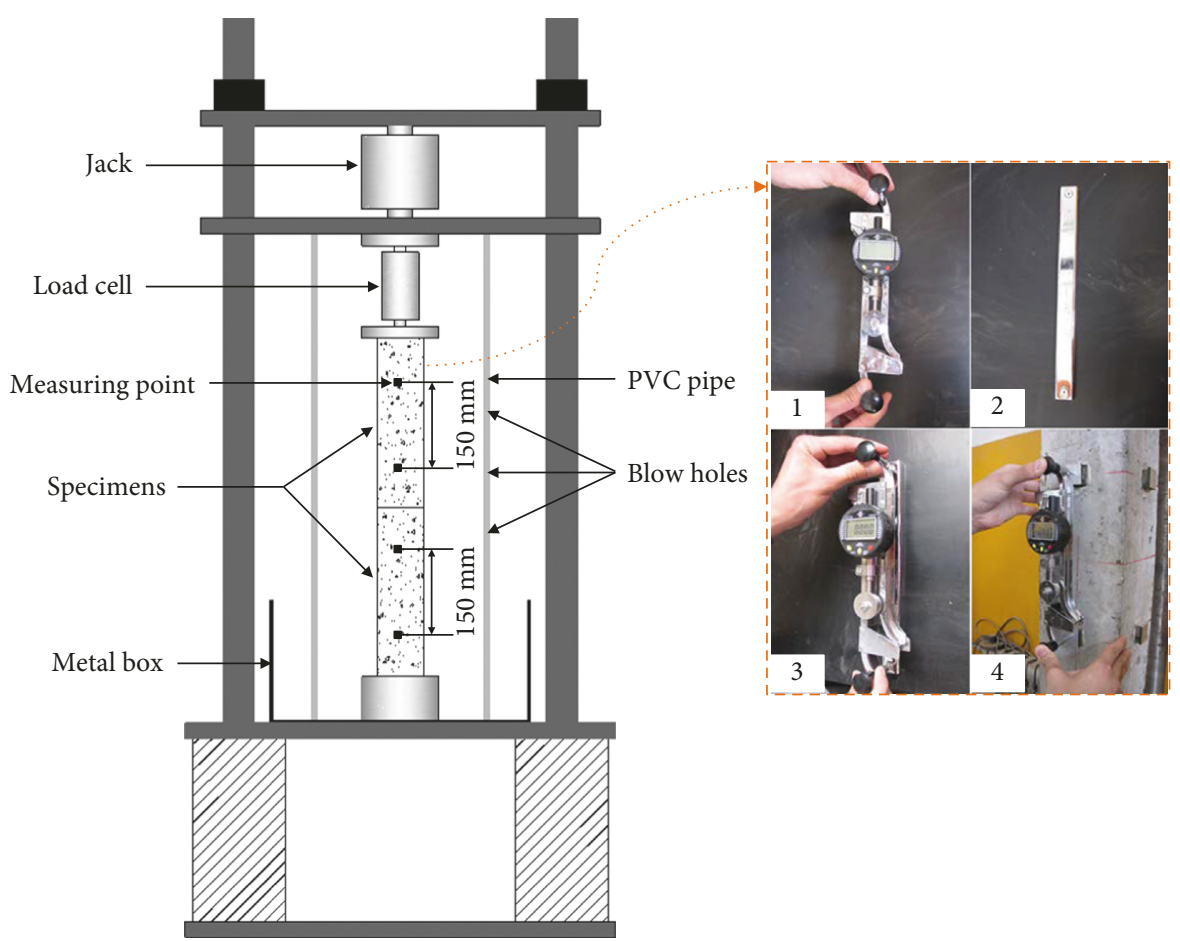

Figure 2: Creep test setup.

Table 4 shows the details of the RC beams used for the long-term deflection test. The loading age, exposure conditions, and spray system were identical to those employed in the creep test. Specimens ST-1 and ST-2 were monotonically loaded to failure under four-point bending to obtain the peak load of the beam, as shown in Figure 4. Five out of eight beams were subjected to sustained loading in a four-point bending configuration, and the loading level was $30 \%$ of the ultimate load $(9 \mathrm{kN})$, as shown in Figure 5.

The midspan deflection of each beam was measured using linear voltage displacement transducers (LVDTs) every day. Beams LD-A-S, LD-B-S, and LD-C-S were tested to avoid the effects of shrinkage on their long-term properties. The deflection of each beam can be calculated using 
TABle 3: Details of the prismatic specimens used for the creep tests in the present study.

\begin{tabular}{lcccc}
\hline Specimen & Loading age (day) & Loading level $(\mathrm{kN})$ & Exposure ID & Exposure condition \\
\hline CR-A-1 & 43 & 276 & 1 & Natural air \\
CR-A-2 & 43 & 276 & 1 & 1 \\
CR-A-S & 43 & 276 & 2 & Sprayed with water (99\% RH) for 7 days and \\
CR-B-1 & 43 & 276 & 2 & dried with natural air for 7 days \\
CR-B-2 & 43 & - & 2 & Sprayed with water (99\% RH) for 1 day and \\
CR-B-S & 43 & 276 & 3 & dried with natural air for 1 day \\
CR-C-1 & 43 & 276 & 3 & 3 \\
CR-C-2 & 43 & - & & \\
CR-C-S & 43 & & 3
\end{tabular}

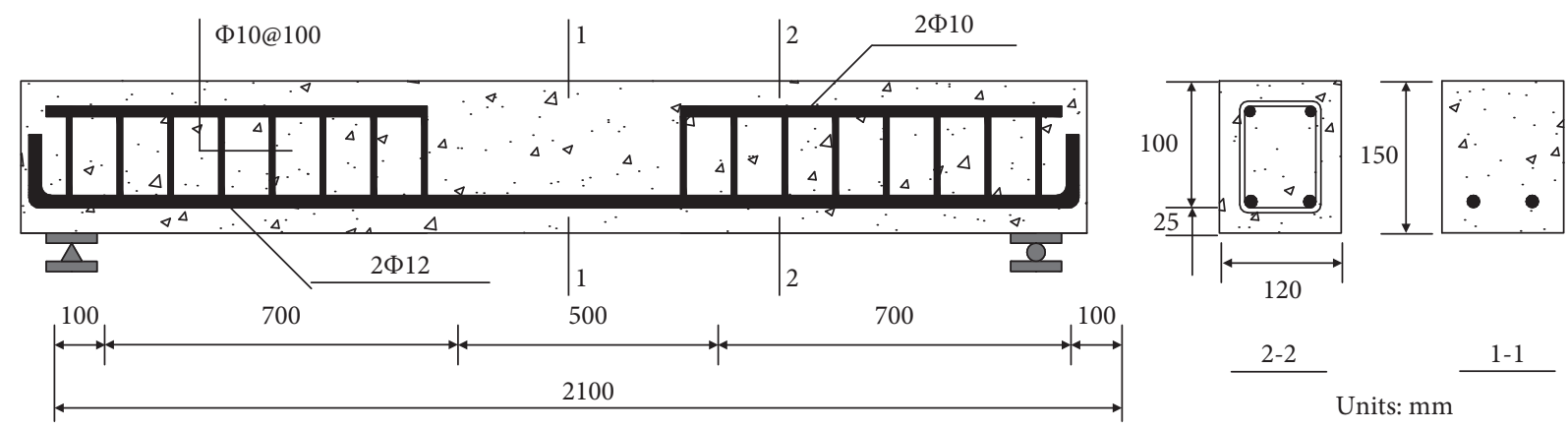

Figure 3: Dimensions and reinforced bar properties of the RC beams.

TABLE 4: Details of prismatic specimens used for creep test in the present study.

\begin{tabular}{lcccc}
\hline Specimen & Loading age (day) & Loading level $(\mathrm{kN})$ & Exposure ID & Exposure condition \\
\hline LD-A-1 & 43 & 276 & 1 & Natural air \\
LD-A-S & 43 & - & 1 & 2 \\
LD-B-1 & 43 & 276 & 2 & Sprayed with water (99\% RH) for 7 days and \\
LD-B-2 & 43 & - & 2 & dried with natural air for 7 days \\
LD-B-S & 43 & 276 & 3 & Sprayed with water (99\% RH) for 1 day and \\
LD-C-1 & 43 & 276 & 3 & dried with natural air for 1 day \\
LD-C-2 & 43 & - & 3 & Monotonically tested up to failure \\
LD-C-S & 43 & & & \\
ST-1 & 43 & 43 &
\end{tabular}

$$
\delta_{\mathrm{cp}}\left(t, t_{0}\right)=\delta_{\mathrm{e}}\left(t, t_{0}\right)-\delta_{\mathrm{sh}}\left(t, t_{0}\right)
$$

where $\delta_{\mathrm{cp}}\left(t, t_{0}\right)$ and $\delta_{\mathrm{sh}}\left(t, t_{0}\right)$ are the deflections due to creep and shrinkage, respectively, and $\delta_{\mathrm{e}}\left(t, t_{0}\right)$ is the midspan deflection measured by LVDTs.

\section{Results and Discussion}

The creep and long-term deflection tests both lasted for 331 days. Figure 6 shows the variable temperature and humidity data that were recorded regularly over the 331-day period.

3.1. Creep Strain. Figure 7 shows the creep strain curves for the specimens under exposure condition 1 (natural air).
The development of creep strain could be divided into three stages. During the first 10 days after loading, the creep strain increased considerably, and the deformation rate decreased gradually. During the approximate period from 10 to 250 days after loading, the creep stain increased linearly. Beyond 250 days after loading, the creep strain tended to increase more slowly and eventually became relatively stable.

Figure 8 displays the humidity data and creep strain curves for the specimens under exposure conditions 2 and 3. Note that the RH was maintained at $99 \%$ during the wetting cycle.

The creep strain curves of the specimens under exposure conditions 2 and 3 both exhibit approximately linear tendencies that are evidently different from those of the specimens exposed to only natural air. During certain wetting cycles, the deformation rate increased more slowly, 


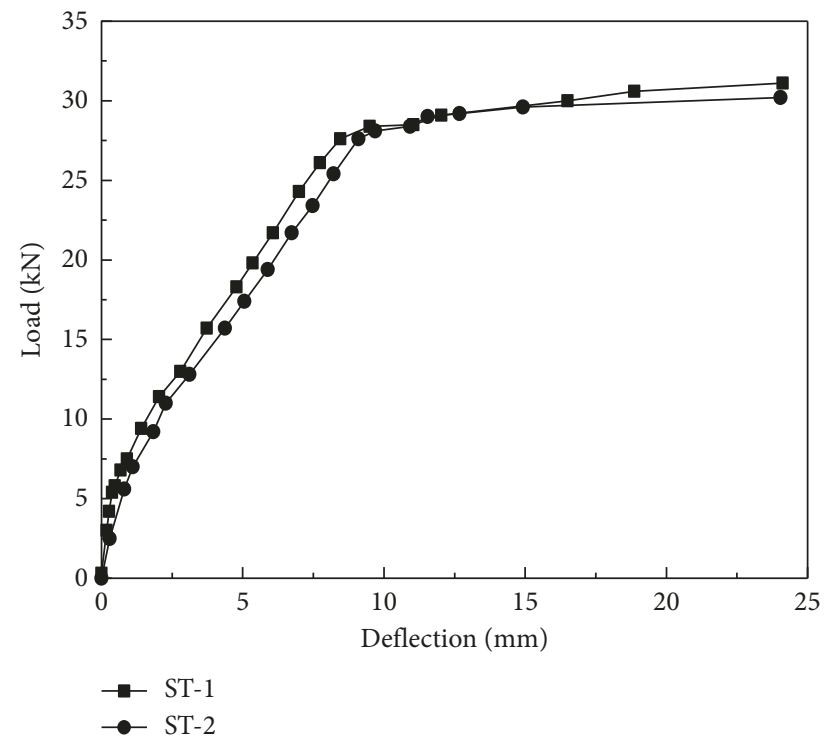

FIGURE 4: Static test results for specimens ST-1 and ST-2.

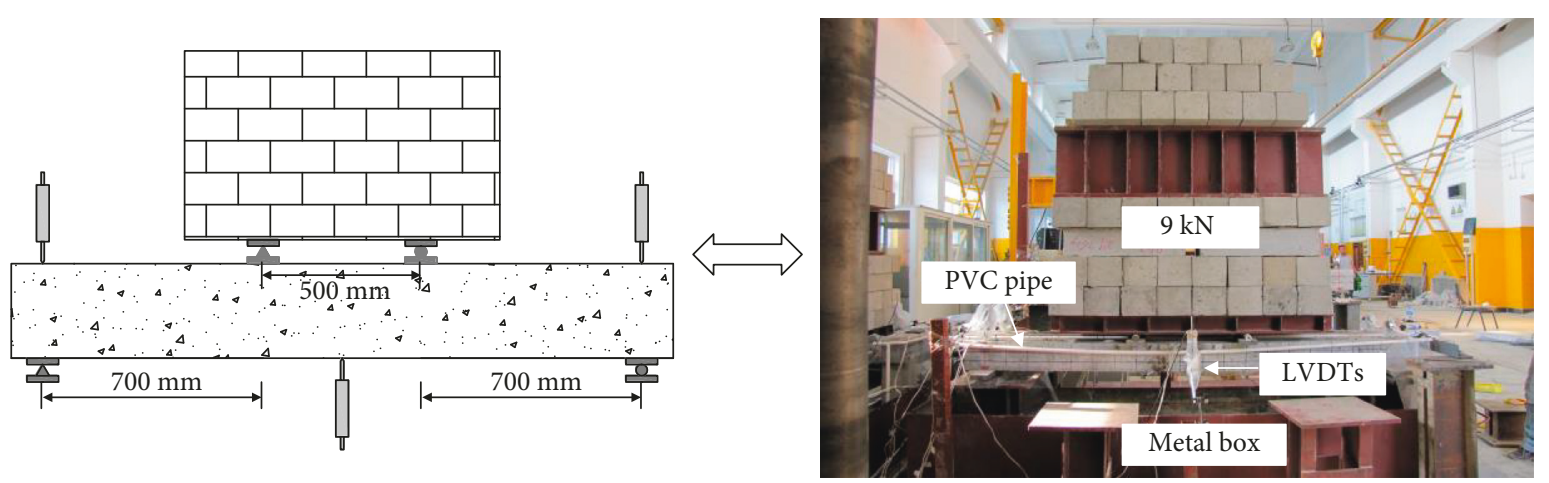

FIgURE 5: Schematic of the sustained loading test setup.

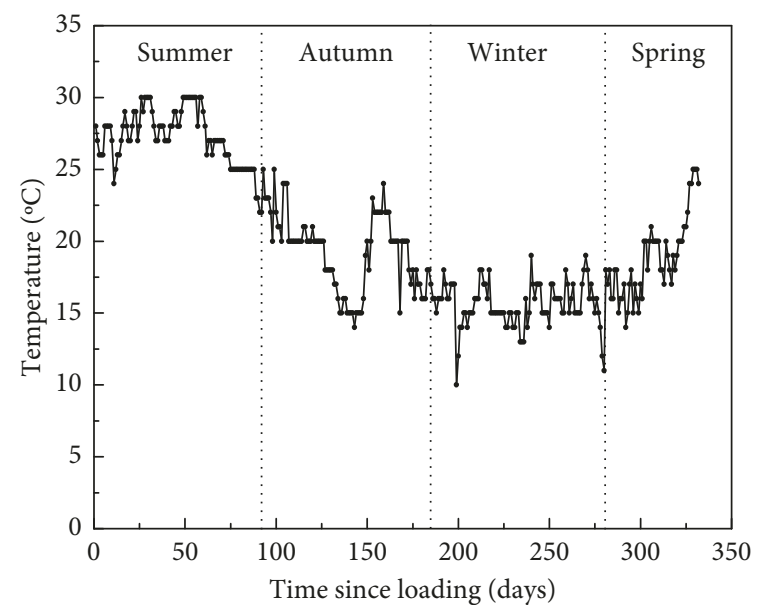

(a)

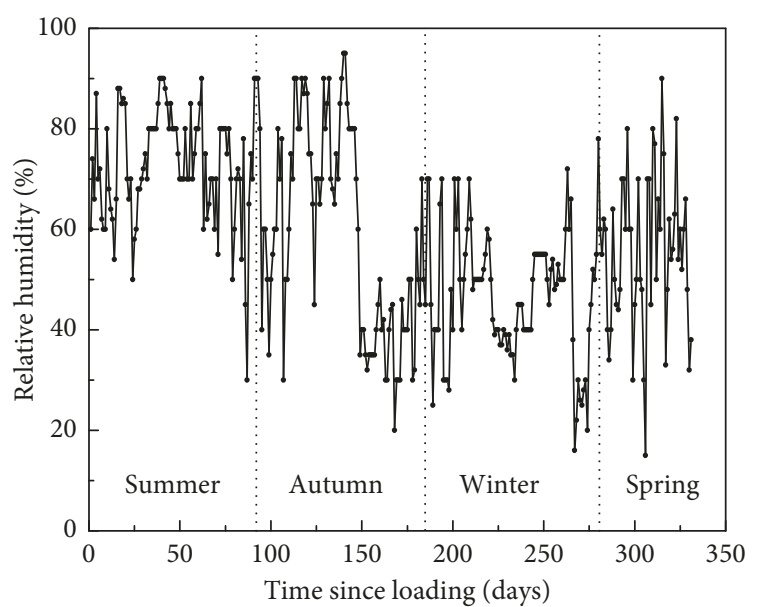

(b)

FIGURE 6: Temperature and humidity variations: (a) temperature; (b) relative humidity.

and the creep strain could have even recovered with an increase in the humidity, especially under exposure condition 3.
The creep curves of specimens CR-A-1, CR-B-1, and CRC-1 and their creep strain at 331 days after the onset of loading are shown in Figure 9. The effects of cyclic wetting 


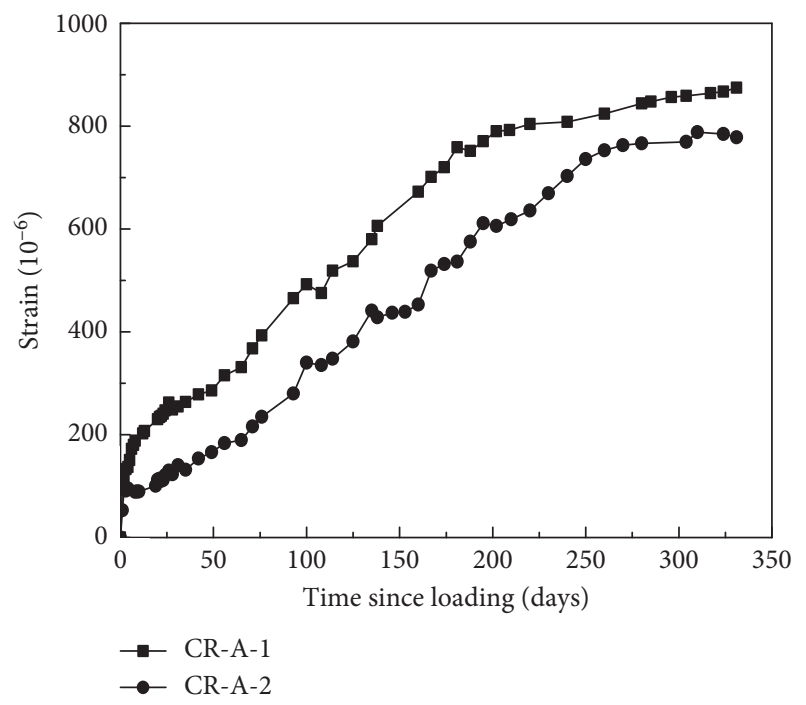

Figure 7: Creep strain curves for specimens CR-A-1 and CR-A-2.
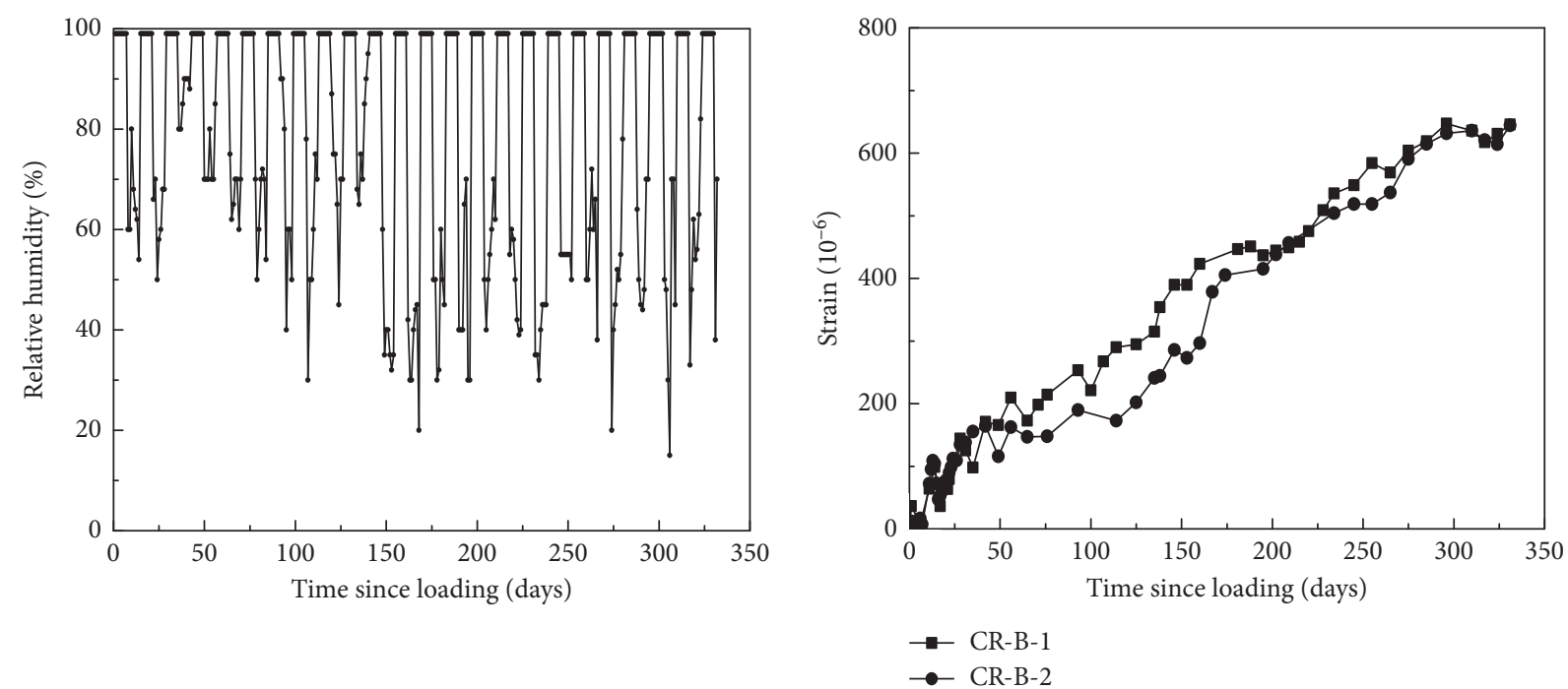

(a)

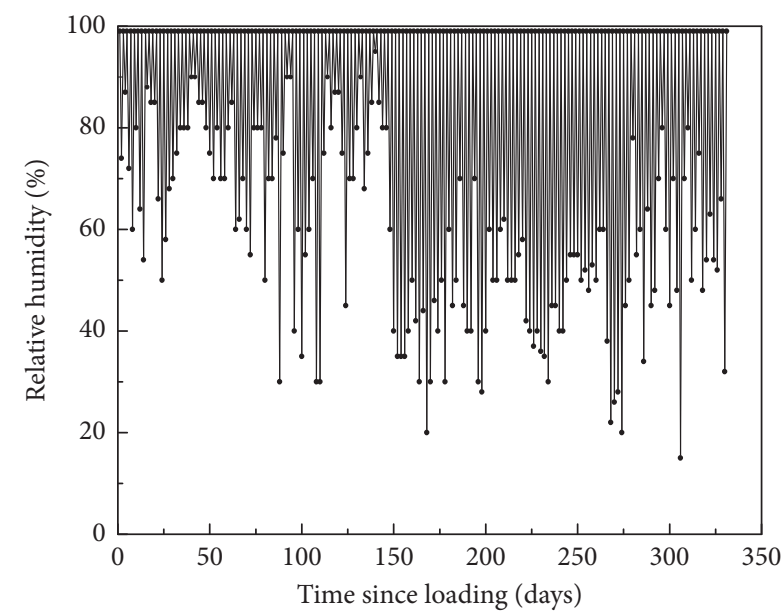

(b)

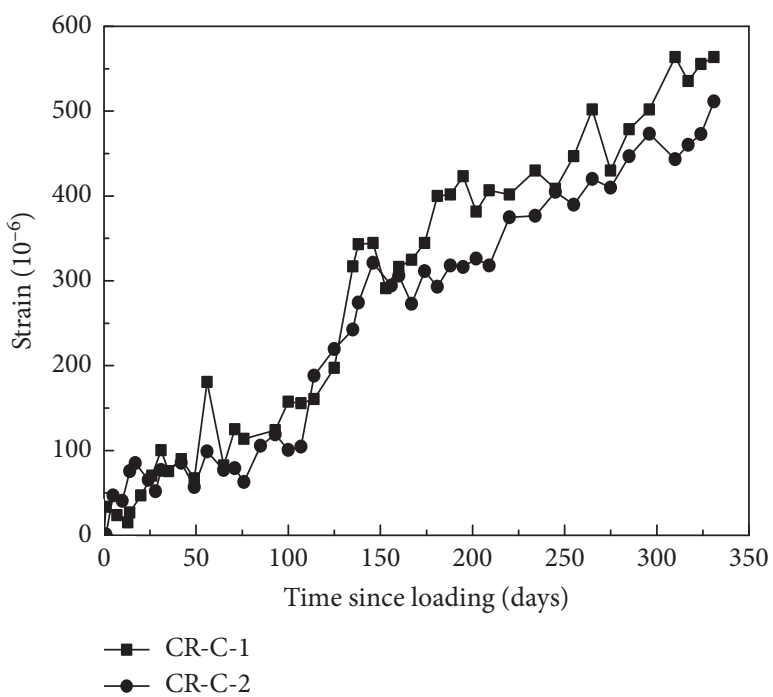

(c)

(d)

FIGURE 8: Humidity data and creep strain curves: (a) humidity (exposure condition 2); (b) creep strain curves for specimens CR-B-1 and CRB-2; (c) humidity (exposure condition 3); (d) creep strain curves for specimens CR-C-1 and CR-C-2. 


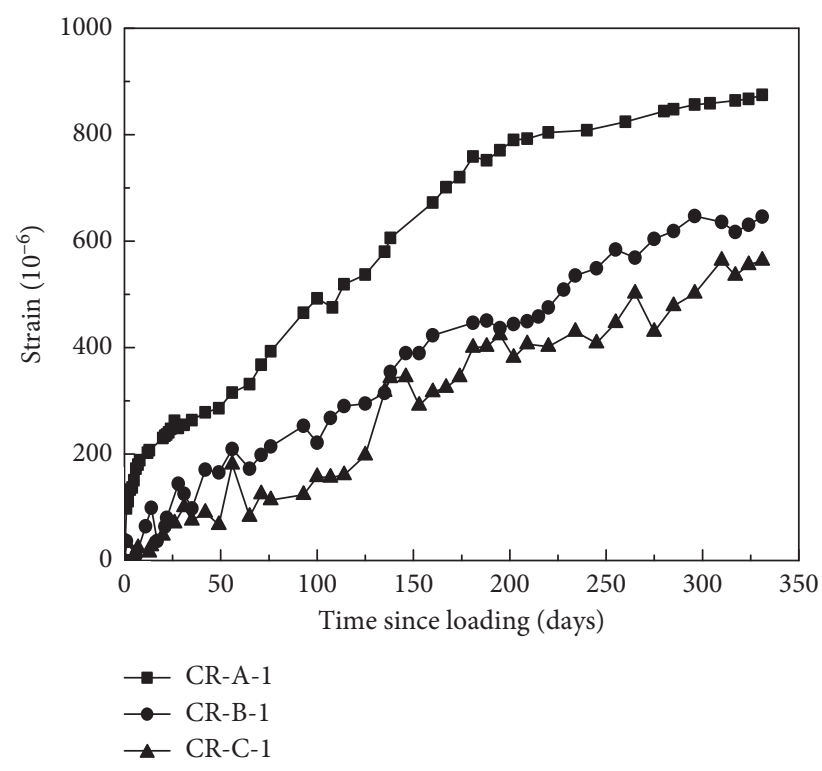

(a)

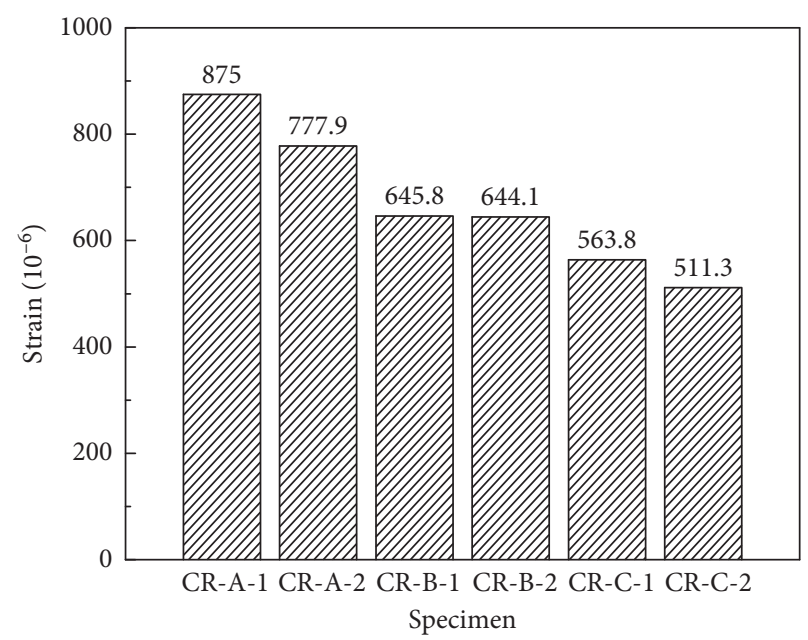

(b)

FIGURE 9: Creep strains of the specimens under different exposure conditions: (a) comparison of creep strain curves; (b) comparison of creep strain at 331 days since loading.

and drying obviously decreased both the deformation rates and the creep strain of the specimens. The creep strain at 331 days after loading the specimens under exposure conditions 2 and 3 declined by approximately $22 \%$ and 35\%, respectively, compared with the specimens loaded under exposure condition 1. Meanwhile, under exposure conditions 2 and 3, no obvious differences in the creep strain were observed during the first 30 days. After 30 days, however, a shorter wetting-drying cycle (exposure condition 3) decreased the deformation rate; furthermore, the creep strain at 331 days after the onset of loading under exposure conditions 3 declined by approximately $16.7 \%$ compared with that under exposure condition 2.

3.2. Creep Coefficient. The creep coefficient is often used to evaluate the ability of concrete to experience creep, and it can be defined as the ratio of the creep strain to the elastic strain, as shown in

$$
\varphi\left(t, t_{0}\right)=\frac{\varepsilon_{\mathrm{cp}}\left(t, t_{0}\right)}{\sigma_{\mathrm{c}} / E(28)},
$$

where $\varphi\left(t, t_{0}\right)$ is the creep coefficient, $\varepsilon_{\mathrm{cp}}\left(t, t_{0}\right)$ is the creep strain, $\sigma_{c}$ and $E(28)$ are the loading stress and the elastic modulus at 28 days, respectively.

As shown in Figure 10, the curves of the creep coefficients of the specimens in this study versus the time since loading are compared with analytical predictions acquired using the procedures proposed in ACI 209R [27] and CEBFIP 90 [26]. Table 5 displays the RH data and the analytical results from these analytical methods. Note that the humidity was considered constant in these methods and that the average $\mathrm{RH}$ of the three exposure conditions was employed.
As shown in Figure 10, the creep coefficients provided by the CEB-FIP 90 [26] and ACI 209R [27] models all decreased with an increase in the average humidity, and there were rather large errors between the predicted results and the test data. The prediction curves estimated a higher increasing rate during the first 100 days and prematurely entered a stable stage at approximately 150 days. At 331 days after the onset of loading, the average ratios between the results predicted using the CEB-FIP 90 model and the experimental data under exposure conditions 1,2 , and 3 were $0.65,0.66$, and 0.63 , respectively, while those using the ACR 209R model were $0.66,0.75$, and 0.86 , respectively. Accordingly, the CEB-FIP 90 model is evidently more sensitive to the average humidity.

3.3. Long-Term Deflections of RC Beams. Figure 11 shows the long-term midspan deflection of each RC beam. The curves of the midspan deflections versus the time since loading can be divided into two stages. In the first stage during the first 25 days after loading, the deflections developed quickly and increased approximately from $35 \%$ to $45 \%$ of the total deflection. During the second stage exceeding 25 days after loading, the deflection tended to increase more slowly and became relatively stable.

The effects of the humidity on the long-term deflection were similar to those observed during the creep test. The long-term deflection decreased with an increase in the average humidity. Cyclic wetting and drying obviously caused a decrease in the deflections. The midspan deflections at 331 days after loading of the beams under exposure conditions 2 and 3 declined by approximately $10 \%$ and $22 \%$, respectively, compared with exposure condition 1. 


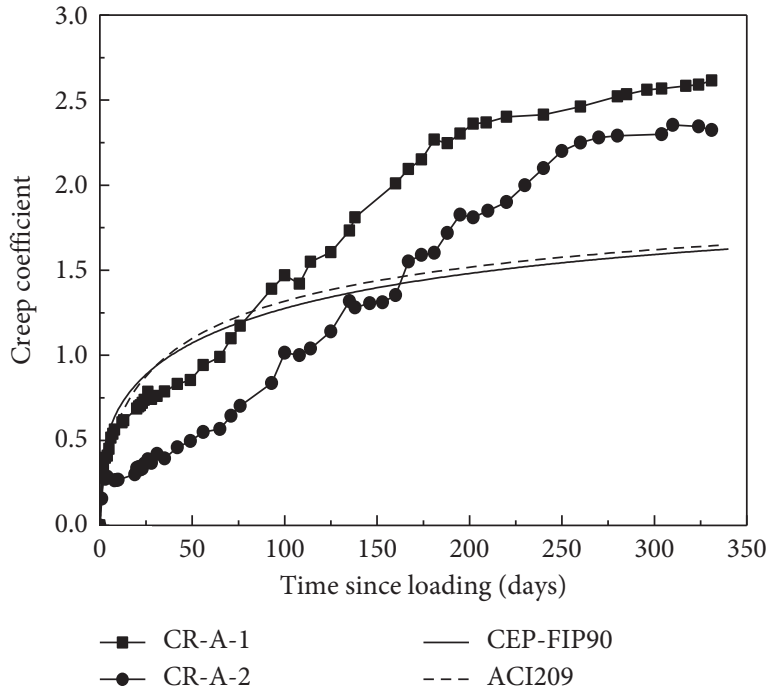

(a)

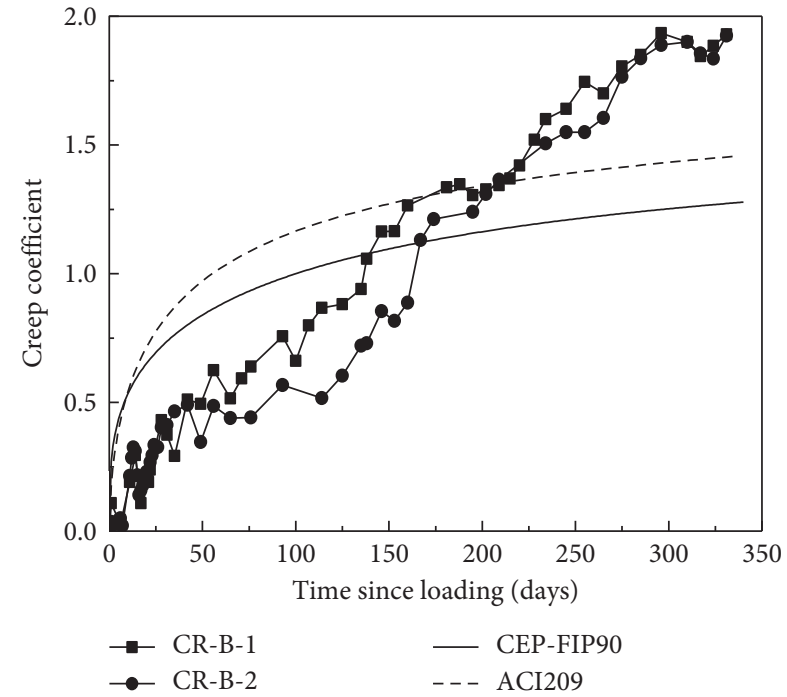

(b)

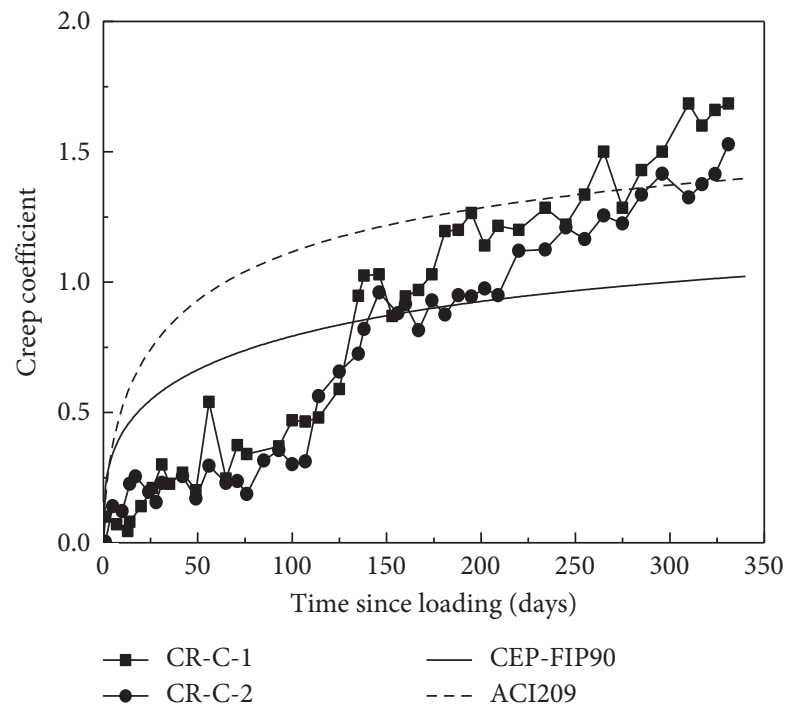

(c)

FIGURE 10: Creep coefficients compared with the analytical model: (a) specimens CR-A-1 and CR-A-2; (b) specimens CR-B-1 and CR-B-2; (c) specimens CR-C-1 and CR-C-2.

TABle 5: Parameters and calculated results for the predicted creep coefficients.

\begin{tabular}{lcccccc}
\hline Specimen & RH (\%) & $t_{0}$ (day) & $t$ (day) & Creep coefficient (ACI 209R [23]) & $\begin{array}{c}\text { Creep coefficient (CEB-FIP90 [22]) } \\
\text { Creep coefficient } \\
\text { (experiment) }\end{array}$ \\
\hline CR-A-1 & 60 & 43 & 331 & 1.64 & 1.62 & 2.62 \\
CR-A-2 & 60 & 43 & 331 & 1.64 & 1.62 & 1.27 \\
CR-B-1 & 75 & 43 & 331 & 1.45 & 1.27 & 1.93 \\
CR-B-2 & 75 & 43 & 331 & 1.45 & 1.02 & 1.93 \\
CR-C-1 & 80 & 43 & 331 & 1.39 & 1.02 & 1.69 \\
CR-C-2 & 80 & 43 & 331 & 1.39 & & 1.53 \\
\hline
\end{tabular}

The ACI 209R [27] model provides a simplified method for predicting the long-term deflection of an RC beam due to creep. The midspan deflection $\delta\left(t, t_{0}\right)$ can be calculated as follows:

$$
\delta\left(t, t_{0}\right)=\xi_{\mathrm{r}} \varphi\left(t, t_{0}\right) \delta_{\mathrm{i}}
$$

where $\varphi\left(t, t_{0}\right)$ is the creep coefficient, $\delta_{\mathrm{i}}$ is the instantaneous deflection at the time $t_{0}$ when the load is first applied, and $\xi_{\mathrm{r}}$ 


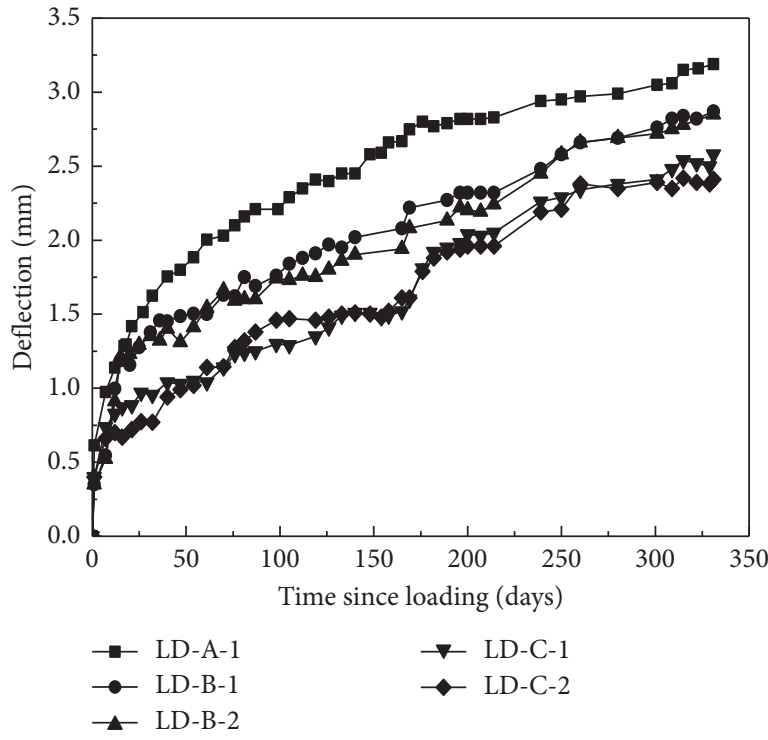

(a)

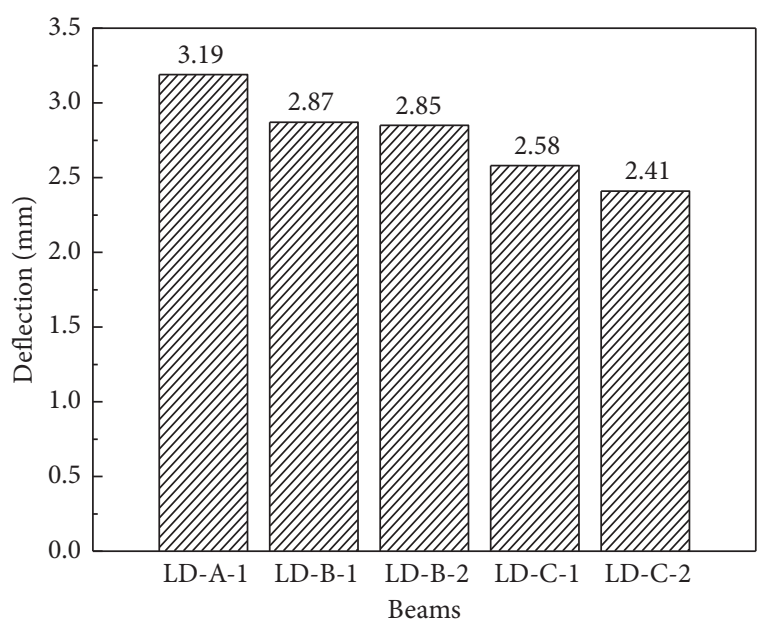

(b)

FIGURE 11: Long-term deflection of RC beams under different exposure conditions: (a) comparison of long-term deflection curves; (b) comparison of deflections at 331 days since loading.

is a factor to account for the movement of a neutral axis and the inclusion of compression steel in the reinforced member $A_{s}^{\prime}$ and the inclusion of tension reinforcing steel $A_{s} \cdot \xi_{\mathrm{r}}$ can be calculated using

$$
\xi_{\mathrm{r}}=0.85-0.45\left(\frac{A_{\mathrm{s}}^{\prime}}{A_{\mathrm{s}}}\right) \geq 0.4
$$

No top-layer steel bars were used in the moment span in this study. Therefore, $\xi_{\mathrm{r}}$ was set at 0.85 .

First, the theoretical creep coefficients predicted using the ACI 209R [27] model (as shown in Figure 10) without considering variable humidity were used to predict the long-term deflection of each RC beam. Figure 12 shows the predicted results compared with the test data. The instantaneous deflection and the predicted deflection at 331 days since the loading of each beam are shown in Table 6.

As shown in Figure 12, the ACI 209R [27] model generated smaller predictions for all of the beams, and the average ratios between the predicted and experimental data under exposure conditions 1,2 , and 3 were $0.71,0.74$, and 0.80 , respectively.

The creep coefficients obtained from the creep test (as shown in Figure 10) were then used to predict the long-term deflection of each RC beam. Figure 13 shows a comparison between the test data and the predicted results, from which it is clear that the predicted deflections at 331 days after loading (acquired using the creep coefficients obtained from the creep test) exhibit a higher accuracy and show good agreement with the experimental results.

\section{Conclusions}

The creep behaviors of concrete and the long-term deflections of RC beams under sustained loading and variable humidity conditions were investigated in this study. The following conclusions can be drawn:

(1) Tests of the creep behavior revealed that the effects of cyclic wetting and drying obviously decreased both the deformation rates and the creep strains of the prismatic specimens. The creep strains at 331 days after loading the specimens under exposure conditions 2 and 3 declined by approximately $22 \%$ and $35 \%$, respectively, relative to those under exposure condition 1 .

(2) The creep strain curves of the specimens under exposure conditions 2 and 3 exhibited approximately linear tendencies in obvious contrast to the specimens exposed to natural air. During certain wetting cycles, the deformation rate became slower, and the creep strain potentially even recovered with an increase in the humidity, especially under exposure condition 3 .

(3) Theoretical calculations of the creep coefficients predicted using ACI 209R [27] and CEB-FIP 90 [26] were compared with the experimental data. The findings revealed rather large errors between the predicted results and the test data when the average $\mathrm{RH}$ was adopted in the analytical models.

(4) Similar to the results from the creep test, the longterm deflection decreased with an increase in the average humidity. Cyclic wetting and drying 


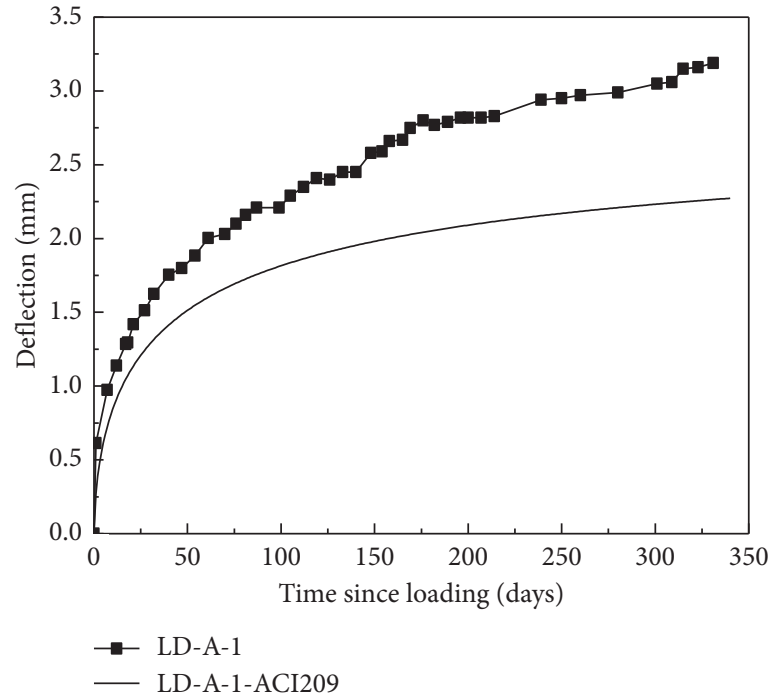

(a)

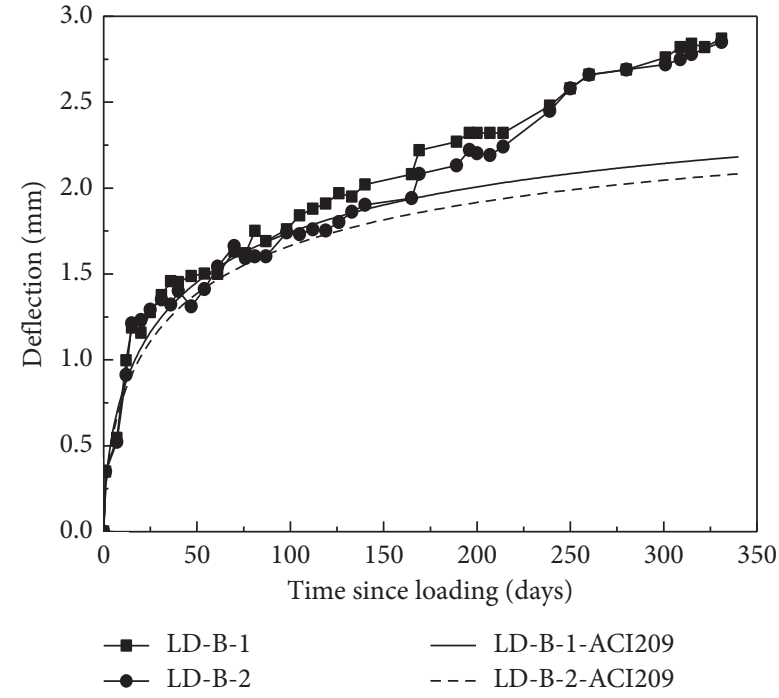

(b)

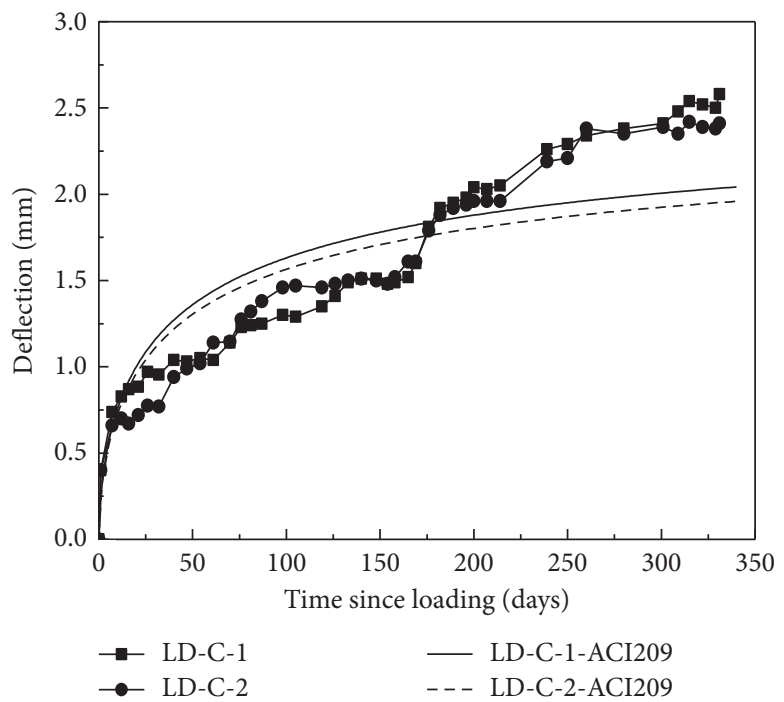

(c)

Figure 12: Long-term deflections compared with the analytical model: (a) Beam LD-A-1; (b) Beams LD-B-1 and LD-B-2; (c) Beams LD-C-1 and LD-C-2.

TABle 6: Parameters and the predicted deflections at 331 days after loading.

\begin{tabular}{lcccccc}
\hline Specimen & RH $(\%)$ & $t_{0}$ (day) & $t$ (day) & $\delta_{\mathrm{i}}(\mathrm{mm})$ & Deflection (ACI 209R) & Deflection (experiment) \\
\hline LD-A-1 & 60 & 43 & 331 & 1.62 & 2.27 & 3.19 \\
LD-B-1 & 75 & 43 & 331 & 1.76 & 2.18 & 2.87 \\
LD-B-2 & 75 & 43 & 331 & 1.68 & 2.08 & 2.85 \\
LD-C-1 & 80 & 43 & 331 & 1.72 & 2.04 & 2.58 \\
LD-C-2 & 80 & 43 & 331 & 1.65 & 1.96 & 2.41 \\
\hline
\end{tabular}

obviously decreased the deflections of RC beams.

(5) The simplified method proposed in the ACI 209R [27] model was used to predict the long-term deflections of RC beams due to creep effects, the results of which were compared with the test data. The results demonstrated that the predicted deflections at 331 days after loading (acquired using the creep coefficients obtained from the creep test) 


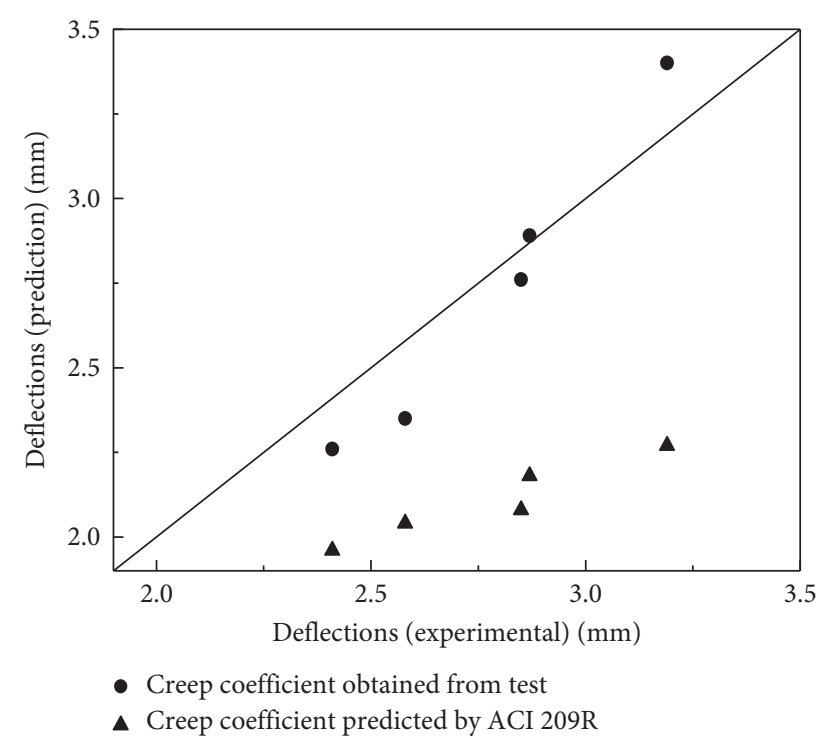

Figure 13: Predicted deflections at 331 days after loading compared with the test data.

exhibit a higher accuracy and show good agreement with the experimental results.

\section{Data Availability}

The data used to support the findings of this study are included within the article.

\section{Conflicts of Interest}

The authors declare that they have no conflicts of interest.

\section{Acknowledgments}

This work was supported by the National Natural Science Foundation of China and the projects of Chongqing Science and Technology Commission (Nos. 51709026 and cstc2017jcyjA1662).

\section{References}

[1] A. M. Neville, "Properties of concrete," in Longman, vol. 4, Pearson, London, UK, 1995.

[2] Z. P. Bažant, "Prediction of concrete creep and shrinkage: past, present and future," Nuclear Engineering and Design, vol. 203, no. 1, pp. 27-38, 2001.

[3] V. C. Li, "Tailoring ECC for special attributes: a review," International Journal of Concrete Structures and Materials, vol. 6, no. 3, pp. 135-144, 2012.

[4] Z. Pan and S. Meng, "Three-level experimental approach for creep and shrinkage of high-strength high-performance concrete," Engineering Structures, vol. 120, pp. 23-36, 2016.

[5] S. Seara-Paz, B. González-Fonteboa, F. Martínez-Abella, and I. González-Taboada, “Time-dependent behaviour of structural concrete made with recycled coarse aggregates. Creep and shrinkage," Construction and Building Materials, vol. 122, pp. 95-109, 2016.

[6] S. L. Bakoss, R. I. Gilbert, K. A. Faulkes, and V. A. Pulmano, "Long-term deflections of reinforced concrete beams,"
Magazine of Concrete Research, vol. 34, no. 121, pp. 203-212, 1982.

[7] R. Somna, C. Jaturapitakkul, P. Rattanachu, and W. Chalee, "Effect of ground bagasse ash on mechanical and durability properties of recycled aggregate concrete," Materials \& Design (1980-2015), vol. 36, pp. 597-603, 2012.

[8] S. Hong and S. K. Park, "Long-term behavior of fiberreinforced-polymer-plated concrete beams under sustained loading: analytical and experimental study," Composite Structures, vol. 152, pp. 140-157, 2016.

[9] Z. P. Bažant and J. K. Kim, "Improved prediction model for time-dependent deformations of concrete: part 4-temperature effects," Materials and Structures, vol. 25, no. 2, pp. 84-94, 1992.

[10] Y. Wei, W. Guo, and S. Liang, "Microprestress-solidification theory-based tensile creep modeling of early-age concrete: considering temperature and relative humidity effects," Construction and Building Materials, vol. 127, pp. 618-626, 2016.

[11] H. Ye, "Creep mechanisms of calcium-silicate-hydrate: an overview of recent advances and challenges," International Journal of Concrete Structures and Materials, vol. 9, no. 4, pp. 453-462, 2015.

[12] H. Ye, C. Fu, N. Jin, and X. Jin, "Influence of flexural loading on chloride ingress in concrete subjected to cyclic dryingwetting condition," Computers and Concrete, vol. 15, no. 2, pp. 183-198, 2015.

[13] W. Ladaoui, T. Vidal, A. Sellier, and X. Bourbon, "Analysis of interactions between damage and basic creep of HPC and HPFRC heated between 20 and $80^{\circ} \mathrm{C}$," Materials and Structures, vol. 46, no. 1-2, pp. 13-23, 2013.

[14] T. P. Huynh, C. L. Hwang, and A. H. Limongan, "The longterm creep and shrinkage behaviors of green concrete designed for bridge girder using a densified mixture design algorithm," Cement and Concrete Composites, vol. 87, pp. 79-88, 2018.

[15] S. A. Kristiawan and A. P. Nugroho, "Creep behaviour of self-compacting concrete incorporating high volume fly ash and its effect on the long-term deflection of reinforced concrete beam," Procedia Engineering, vol. 171, pp. 715-724, 2017.

[16] C. Mias, L. Torres, A. Turon, and I. A. Sharaky, "Effect of material properties on long-term deflections of GFRP reinforced concrete beams," Construction and Building Materials, vol. 41, pp. 99-108, 2013.

[17] A. R. Marí, J. M. Bairán, and N. Duarte, "Long-term deflections in cracked reinforced concrete flexural members," Engineering Structures, vol. 32, no. 3, pp. 829-842, 2010.

[18] V. S. Ramachandran and J. J. Beaudoin, Handbook of Analytical Techniques in Concrete Science and Technology: Principles, Techniques and Applications, Elsevier, Amsterdam, Netherlands, 2000.

[19] F. H. Wittmann, Z. P. Bažant, F. Alou, J.-K. Kim, and A. Wedding, "Statistics of shrinkage test data," Cement, Concrete and Aggregates, vol. 9, no. 2, pp. 129-153, 1987.

[20] T. Ishida, T. Kishi, and K. Maekawa, Multi-Scale Modeling of Structural Concrete, CRC Press, Boca Raton, FL, USA, 2014.

[21] Z. P. Bažant, A. B. Hauggaard, S. Baweja, and F. J. Ulm, "Microprestress-solidification theory for concrete creep. I: aging and drying effects," Journal of Engineering Mechanics, vol. 123, no. 11, pp. 1188-1194, 1997.

[22] G. Pickett, "The effect of Chang in moisture-content on the creep of concrete under a sustained load," ACI Journal Proceedings, vol. 38, pp. 333-356, 1942. 
[23] C. J. Bernhardt, "Creep and shrinkage of concrete," Materials and Constructions, vol. 2, no. 2, pp. 145-152, 1969.

[24] Z. P. Bažant, J. H. Hemann, H. Koller, and L. J. Najjar, "A thinwall cement paste cylinder for creep tests at variable humidity or temperature," Materials and Constructions, vol. 6, no. 4, pp. 277-281, 1973.

[25] Z. P. Bažant and S. T. Wu, "Creep and shrinkage law for concrete at variable humidity," ASCE Journal of the Engineering Mechanics Division, vol. 100, no. 6, pp. 1183-1209, 1974.

[26] CEB-FIP. M. 90, Design of Concrete Structures, CEB-FIPModel-Code 1990, British Standard Institution, London, UK, 1993.

[27] American Concrete Institute, Prediction of Creep, Shrinkage and Temperature Effects in Concrete Structures, American Concrete Institute, Farmington Hills, MI, USA, 1992. 


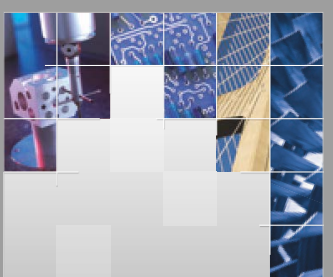

\section{Enfincering}
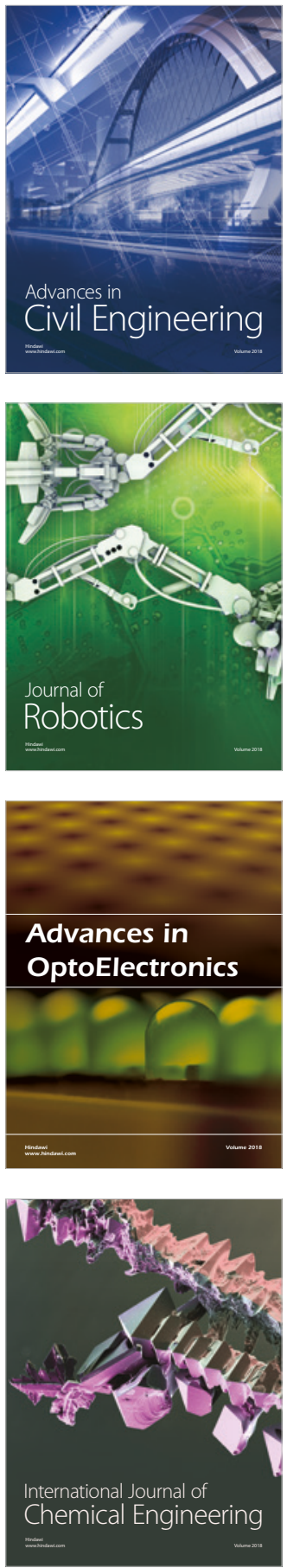

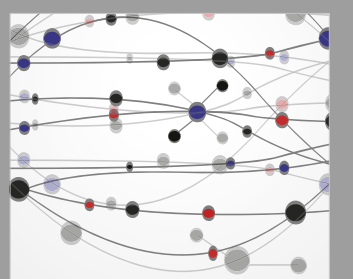

\section{Rotating \\ Machinery}

The Scientific World Journal

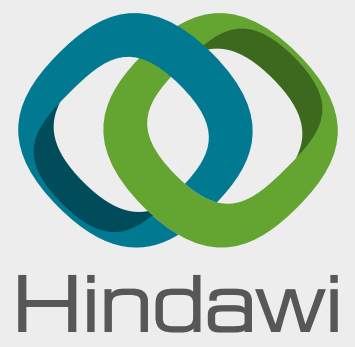

Submit your manuscripts at

www.hindawi.com
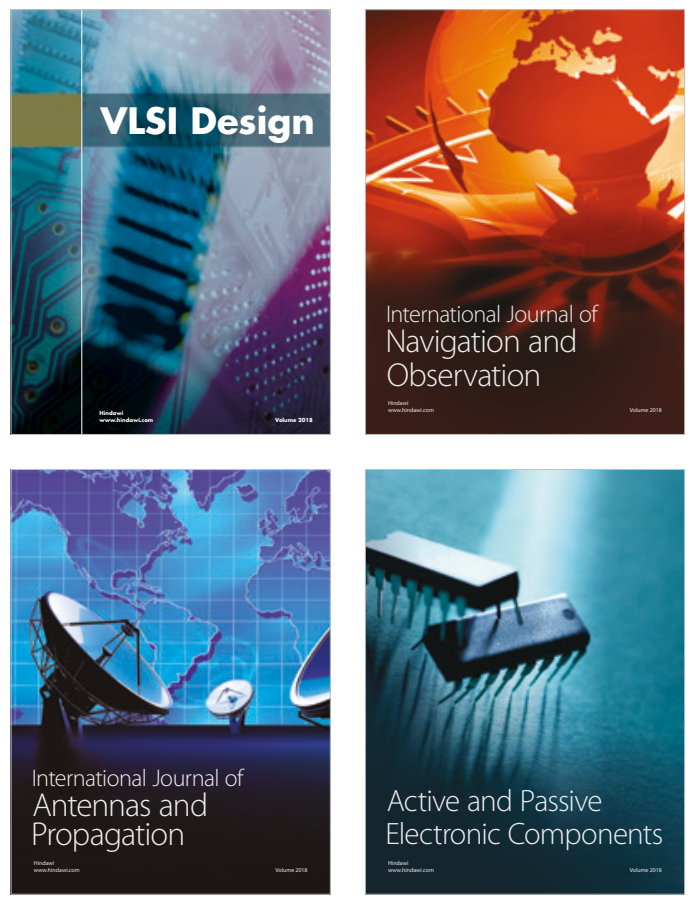
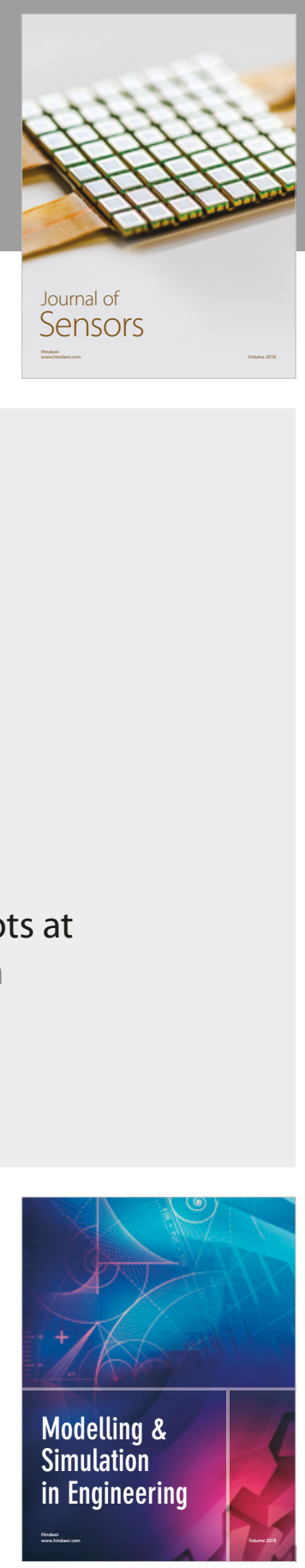

\section{Advances \\ Multimedia}
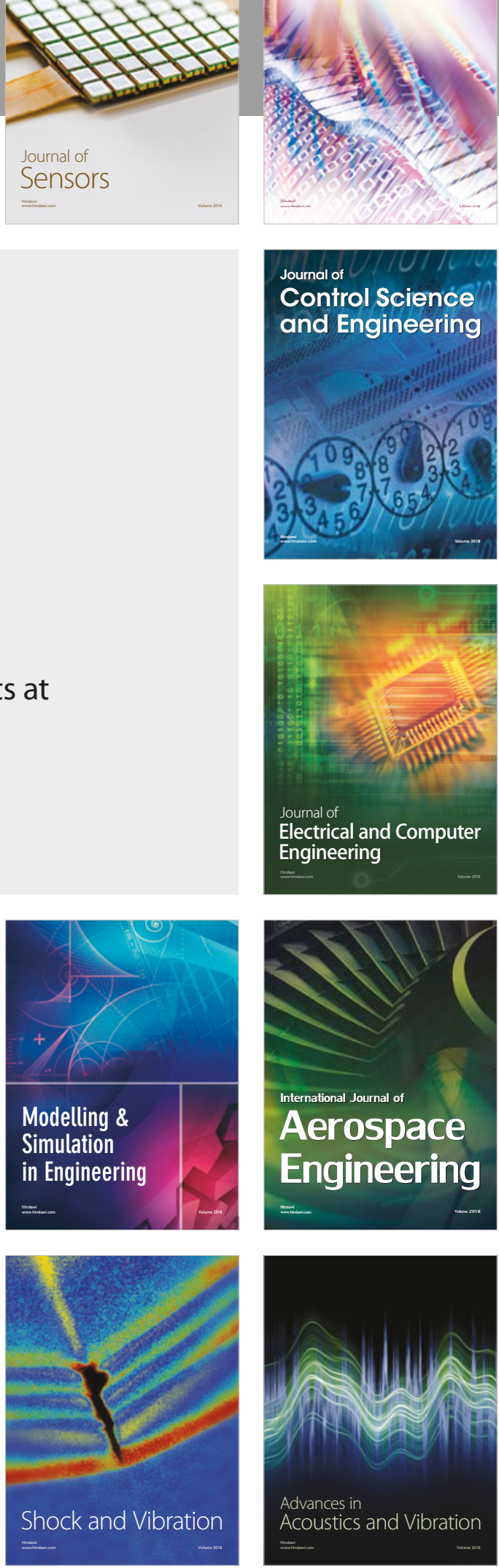